\title{
Taxes, Federal Grants, Local Public Spending, and Growth
}

\author{
HENG-FU ZOU ${ }^{1}$
}

Public Economics Division, Policy Research Department, The World Bank, Washington, DC 20433

and

Institute of Advanced Economic Studies, Wuhan University, Wuhan, China

R eceived A ugust 3, 1994; revised F ebruary 9, 1995

\begin{abstract}
In a dynamic model with both private and local public capital accumulation, this paper examines how federal and local income taxes, local consumption tax, and federal matching grants for local public consumption and local public investment affect the long-run equilibrium (equilibria) of private consumption, private capital accumulation, local public consumption, and local public capital stock. () 1996 A cademic Press, Inc.
\end{abstract}

\section{INTRODUCTION}

In a static and utility-maximizing framework, many existing studies have analyzed the effects of intergovernmental grants on local public spending by examining the implied price (substitution) and income effects. ${ }^{2}$ While Zou [13] has examined some dynamic effects of federal grants on local public consumption and investment, tax revenues of the federal government and local governments are assumed to be constant and the effects of taxes, grants, and local public spending on private sector's consumption, production, and investment are totally ignored. To remedy these deficiencies, this paper first presents a model of local economic growth to include both public and private capital accumulation, spillovers between public and private sectors, and dynamic budget balance of federal and local governments. Then, by dividing local public expenditures into public consumption and public investment, it examines how federal income tax, local taxes, and intergovernmental grants (matching grants for local public

${ }^{1}$ The main ideas in this paper were suggested by two referees of this journal on my previous paper (H . Z ou, Journal of Urban Economics, 36, 98-115 (1994)). H ere I acknowledge their contributions to this paper. I also thank R ichard Bird, J an Brueckner, Hamid Davoodi, Shantayanan D evarajan, G unnar E skeland, A nwar Shah, D anyang X ie, and referees for their comments and help. All remaining errors are mine. The opinions expressed here are not necessarily those of the World Bank.

${ }^{2}$ See Gramlich [5]; Gramlich and Galper [6]; Inman [7]; M ieszkowski and Oakland [8]; Rosen [10]; and Wilde [11, 12]; among many others. 
consumption and investment) affect local public investment, private capital formation, local public consumption, and private consumption.

This approach provides us with a convenient framework to study new areas of local and urban finance. First, the integration of both grants and taxes in a dynamic framework offers a different perspective to understand the interactions among taxes and grants and their general-equilibrium effects. In this integrated framework, for example, it can be seen more clearly how incentives for public investment may also become the incentives for private investment, and how budget constraints of the federal and local governments are consolidated to neutralize the effects of some federal grants. Second, while the role of public consumption and public investment in improving private welfare and private capital accumulation has been previously considered (Arrow and Kurz [1], Barro [2], and Devarajan et al. [4]), growth implications of local taxes and federal grants have not been explored in local and urban finance literature. This paper, built on those contributions, explicitly models the externalities of local public capital accumulation on private investment and analyzes how local economic growth responds to various taxes and grants. Thus the model here is broad and realistic enough to allow us to confront the data and make empirical assessments on the growth effects of taxes and grants.

I organize this paper as follows. In Section II, I set up a basic model in which a representative agent's utility function depends on private consumption and local public consumption, and private sector's production is defined on private capital stock and local capital stock. The role of the federal government is to collect an income tax from the private sector and to allocate the proceeds to localities through matching grants for local public consumption and local public investment. A representative local government collects local taxes and receives grants from the federal government and optimally chooses its spending on public consumption and investment; the private sector takes federal government's and local government's actions (taxes, grants, and public spending) as given and optimally decides how much to consume and invest. In Section III, I examine the stability and equilibrium of the resulting dynamic system and analyze the effects of various taxes and grants on the equilibrium values of private consumption, local public consumption, private investment, and local public investment. In Section IV I extend the basic model to a modified A rrow-K urz utility function by defining the representative agent's utility function on both local public consumption and local public capital stock in addition to private consumption. Some significant differences between the basic model and the modified Arrow-Kurz model will be presented. I conclude this study in Section $\mathrm{V}$ by summarizing the main findings and pointing out some direction for future research. 


\section{THE BASIC MODEL}

A representative agent in a typical locality has an increasing, concave, and continuously differentiable utility function defined on private consumption, $c$, and local public consumption $E$ :

$$
\int_{0}^{\infty}[u(c)+v(E)] e^{-\rho t} d t, \quad 0<\rho<1 .
$$

The separability in the utility function greatly simplifies the analysis, but it is not essential for the results obtained in this paper.

The production function of the representative agent has two inputs: private capital stock $k_{\mathrm{p}}$ and local public capital stock $k_{\mathrm{s}}$. Let $y$ denote the output, and

$$
y=y\left(k_{\mathrm{p}}, k_{\mathrm{s}}\right) .
$$

The production function has the properties $y_{1}>0, y_{2}>0, y_{11}<0, y_{22}<$ $0, y_{12}=y_{21}>0$, and $y_{11} y_{22}-y_{12}^{2}>0$; that is to say, the production function is increasing, concave, and continuously differentiable, and, in particular, local public capital stock is complementary to private capital stock in the production. The production function also satisfies the usual Inada conditions: $y_{i} \rightarrow \infty$ as $k_{i}$ approaches zero, and $y_{i} \rightarrow 0$ as $k_{i}$ approaches infinity, for $i=p$ and $\mathrm{s}$.

A t each time period, the federal government collects an income tax from the private sector at the rate $\tau_{f}$; its expenditures consist of two matching grants for local governments: a matching grant for local public investment at the rate $\alpha(0<\alpha<1)$ and a matching grant for local public consumption at the rate $\beta(0<\beta<1)$. If the federal government's budget is always assumed to be balanced, then

$$
\tau_{\mathrm{f}} y=\alpha \dot{k}_{\mathrm{s}}+\beta E,
$$

where $\dot{k}_{\mathrm{s}}$ is the public investment undertaken by a typical local government.

The representative local government collects an income tax at the rate $\tau_{\mathrm{s}}$ on the private sector (the case of the $U$ nited States) and a consumption tax $\tau_{c}$ on private consumption (a resemblance to the sales tax collected by local governments in the U nited States). ${ }^{3}$ These tax rates are often set by the federal governments in many countries and cannot be chosen by local governments, or in the U nited States, they are chosen by local govern-

${ }^{3} \mathrm{~A} / \mathrm{l}$ tax rates in this paper are exogenous parameters. The optimal choices of tax rates and grants will not be considered in this paper; see Zou [14] for a study on the optimal design of federal grants to localities. 
ments and cannot be often changed by local governments. The total revenue of a typical local government consists of a local income tax, a consumption tax, and two matching grants from the federal government; its expenditures are public consumption, $E$, and public investment, $\dot{k}_{s}$. Therefore its budget constraint is

$$
\tau_{\mathrm{s}} y\left(k_{\mathrm{p}}, k_{\mathrm{s}}\right)+\tau_{\mathrm{c}} c+\alpha \dot{k}_{\mathrm{s}}+\beta E=\dot{k}_{\mathrm{s}}+E,
$$

or

$$
\dot{k}_{\mathrm{s}}=\left[\tau_{\mathrm{s}} y\left(k_{\mathrm{p}}, k_{\mathrm{s}}\right)+\tau_{\mathrm{c}} c-(1-\beta) E\right](1-\alpha)^{-1} .
$$

The representative agent's budget constraint is given by the condition that the after-tax income is equal to the total spending on private consumption, $\left(1+\tau_{\mathrm{c}}\right) c$, and private investment, $\dot{k}_{p}$ :

$$
\dot{k}_{\mathrm{p}}=\left(1-\tau_{\mathrm{f}}-\tau_{\mathrm{s}}\right) y\left(k_{\mathrm{p}}, k_{\mathrm{s}}\right)-\left(1+\tau_{\mathrm{c}}\right) c .
$$

I first look at the optimization in the private sector. Taking the time paths of local public consumption $E$, local public capital stock $k_{s}$, and taxes as given, the representative agent maximizes (1) by choosing private consumption $c$ and private capital stock $k_{\mathrm{p}}$

$$
\underset{\left(c, k_{\mathrm{p}}\right)}{\operatorname{Max}} \int_{0}^{\infty}[u(c)+v(E)] e^{-\rho t} d t, \quad 0<\rho<1 .
$$

subject to the budget constraint in (6).

The current-value $\mathrm{H}$ amiltonian function for the representative agent is $H\left(c, k_{\mathrm{p}}, \lambda_{\mathrm{p}}\right)=u(c)+v(E)+\lambda_{\mathrm{p}}\left[\left(1-\tau_{\mathrm{f}}-\tau_{\mathrm{s}}\right) y\left(k_{\mathrm{p}}, k_{\mathrm{s}}\right)-\left(1+\tau_{\mathrm{c}}\right) c\right]$

where $\lambda_{\mathrm{p}}$ is the costate variable.

The necessary conditions for the optimization are given by (6) and

$$
\dot{c}=\frac{u^{\prime}(c)}{-u^{\prime \prime}(c)}\left[\left(1-\tau_{\mathrm{f}}-\tau_{\mathrm{s}}\right) y_{1}\left(k_{\mathrm{p}}, k_{\mathrm{s}}\right)-\rho\right],
$$

plus the transversality condition

$$
\lim _{t \rightarrow \infty} u^{\prime}(c)\left(1+\tau_{\mathrm{c}}\right) k_{\mathrm{p}} e^{-\rho t}=0 .
$$

Similarly, the optimal conditions for the representative local government can be derived. The local government is assumed to maximize the repre- 
sentative agent's welfare by choosing $E$ and $k_{\mathrm{s}}$ while taking the time paths of $c, k_{\mathrm{p}}$, grants, and taxes as given, or

$$
\operatorname{Max}_{\left(E, k_{\mathrm{s}}\right)} \int_{0}^{\infty}[u(c)+v(E)] e^{-\rho t} d t, \quad 0<\rho<1
$$

subject to the budget constraint (5).

The current-value Hamiltonian function for the local government is

$$
\begin{aligned}
H\left(E, k_{\mathrm{s}}, \lambda_{\mathrm{s}}\right)= & {[u(c)+v(E)]+\lambda_{\mathrm{s}}\left[\tau_{\mathrm{s}} y\left(k_{\mathrm{p}}, k_{\mathrm{s}}\right)+\tau_{\mathrm{c}} c-(1-\beta) E\right] } \\
& (1-\alpha)^{-1},
\end{aligned}
$$

where $\lambda_{\mathrm{s}}$ is the costate variable.

The optimal conditions for the local government's optimization are (5)

$$
\dot{E}=\frac{v^{\prime}(E)}{-v^{\prime \prime}(E)}\left[\tau_{\mathrm{s}}(1-\alpha)^{-1} y_{2}\left(k_{\mathrm{p}}, k_{\mathrm{s}}\right)-\rho\right],
$$

and the transversality condition is

$$
\lim _{t \rightarrow \infty} v^{\prime}(E)(1-\beta)(1-\alpha)^{-1} k_{\mathrm{s}} e^{-\rho t}=0 .
$$

In this model, the federal government has been assigned the simple roles of a tax collector and a grantor, because nation-wide public consumption and public investment are excluded from the model. To include these federal expenditures into the model is straightforward, but it is analytically difficult to deal with six differential equations at the same time.

To complete the model setup, it is necessary to integrate the federal government's budget constraint (3) into the necessary conditions for optimization. That can be done easily. Substituting Eq. (3) for $\alpha \dot{k}_{\mathrm{s}}$ in Eq. (4) leads to an integrated budget constraint for the federal and local governments

$$
\dot{k}_{\mathrm{s}}=\left(\tau_{\mathrm{s}}+\tau_{\mathrm{f}}\right) y\left(k_{\mathrm{p}}, k_{\mathrm{s}}\right)+\tau_{\mathrm{c}} c-E,
$$

which says that all tax revenues are allocated to local public investment $\dot{k}_{\mathrm{s}}$ and local public consumption $E$.

Equations (8), (10), (6), and (11) compose a complete dynamic system in the four endogenous variables of the model: private consumption, public consumption, private capital, and public capital. This dynamic system is the focus of the analysis in the next section. 


\section{ANALYSIS}

Proposition 1. The dynamic system in Eqs. (8), (10), (6), and (11) has a unique equilibrium.

Proof. At any equilibrium, $\dot{c}=\dot{E}=\dot{k}_{\mathrm{p}}=\dot{k}_{\mathrm{s}}=0$. Then, the dynamic system is reduced to

$$
\begin{gathered}
\left(1-\tau_{\mathrm{f}}-\tau_{\mathrm{s}}\right) y_{1}\left(\bar{k}_{\mathrm{p}}, \bar{k}_{\mathrm{s}}\right)-\rho=0, \\
\tau_{\mathrm{s}}(1-\alpha)^{-1} y_{2}\left(\bar{k}_{\mathrm{p}}, \bar{k}_{\mathrm{s}}\right)-\rho=0, \\
\left(1-\tau_{\mathrm{f}}-\tau_{\mathrm{s}}\right) y\left(\bar{k}_{\mathrm{p}}, \bar{k}_{\mathrm{s}}\right)-\left(1+\tau_{\mathrm{c}}\right) \bar{c}=0, \\
\left(\tau_{\mathrm{s}}+\tau_{\mathrm{f}}\right) y\left(\bar{k}_{\mathrm{p}}, \bar{k}_{\mathrm{s}}\right)+\tau_{\mathrm{c}} \bar{c}-\bar{E}=0,
\end{gathered}
$$

where $\bar{c}, \bar{E}, \bar{k}_{\mathrm{p}}$, and $\bar{k}_{\mathrm{s}}$ denote the steady-state values of private consumption, public consumption, private capital, and public capital, respectively.

In (12) and (13), since $y_{11} y_{22}-y_{12}^{2}>0$ (as a result of the concavity of the production function), the equilibrium values, $\bar{k}_{\mathrm{p}}$ and $\bar{k}_{\mathrm{s}}$, can be solved uniquely as the functions of parameters $\tau_{\mathrm{s}}, \tau_{\mathrm{f}}, \rho$, and $\alpha$ by the implicit function theorem. Then, with the uniqueness of $\bar{k}_{\mathrm{p}}$ and $\bar{k}_{\mathrm{s}}, \bar{c}$ is unique from Eq. (14). Similarly, with the uniqueness of $\bar{k}_{\mathrm{p}}, \bar{k}_{\mathrm{s}}$, and $\bar{c}$, the unique solution for $\bar{E}$ is given by $\mathrm{Eq}$. (15).

Q.E.D.

PROPOSITION 2. There exists a unique perfect-foresight path in this $d y$ namic system.

Proof. See the A ppendix.

With the uniqueness of the equilibrium and its stability, I proceed to study the comparative dynamics regarding the effects of various taxes and grants on the long-run accumulation of capital stocks. Totally differentiate the equilibrium conditions (12)-(15):

$$
\begin{gathered}
{\left[\begin{array}{cccc}
0 & 0 & \left(1-\tau_{\mathrm{f}}-\tau_{\mathrm{s}}\right) y_{11} & \left(1-\tau_{\mathrm{f}}-\tau_{\mathrm{s}}\right) y_{12} \\
0 & 0 & \tau_{\mathrm{s}}(1-\alpha)^{-1} y_{21} & \tau_{\mathrm{s}}(1-\alpha)^{-1} y_{22} \\
-\left(1+\tau_{\mathrm{c}}\right) & 0 & \left(1-\tau_{\mathrm{f}}-\tau_{\mathrm{s}}\right) y_{1} & \left(1-\tau_{\mathrm{f}}-\tau_{\mathrm{s}}\right) y_{2} \\
\tau_{\mathrm{c}} & -1 & \left(\tau_{\mathrm{f}}+\tau_{\mathrm{s}}\right) y_{1} & \left(\tau_{\mathrm{f}}+\tau_{\mathrm{s}}\right) y_{2}
\end{array}\right]\left[\begin{array}{c}
d c \\
d E \\
d k_{p} \\
d k_{s}
\end{array}\right]} \\
=\left[\begin{array}{c}
y_{1} d \tau_{\mathrm{f}}+y_{1} d \tau_{\mathrm{s}} \\
-y_{2} d \tau_{\mathrm{s}}-\tau_{\mathrm{s}}(1-\alpha)^{-2} y_{2} d \alpha \\
y d \tau_{\mathrm{f}}+y d \tau_{\mathrm{s}}+\bar{c} d \tau_{\mathrm{c}} \\
-y d \tau_{\mathrm{f}}-y d \tau_{\mathrm{s}}-\bar{c} d \tau_{\mathrm{c}}
\end{array}\right]
\end{gathered}
$$


From (16), it is simple to note two implications:

First, a rise in the federal income tax rate $\tau_{f}$ reduces private capital stock, local public capital stock, and private consumption in the long run. Its effect on local public consumption is ambiguous. These results can be explained as follows: while a higher federal income tax reduces the after-tax returns on private investment and leads to a lower private capital accumulation, it also reduces local public investment because a smaller private capital stock lowers the productivity of public capital (note that $y_{12}\left(k_{\mathrm{p}}, k_{\mathrm{s}}\right)>0$ ). Since private consumption is given by (14), a rise in $\tau_{\mathrm{f}}$ reduces consumption both directly (through a reduced after-tax income) and indirectly (through a reduced before-tax income as a result of lower private and public capital stocks). The effect on public consumption is ambiguous because, while a higher federal income tax leads to a smaller consumption tax, $\tau_{\mathrm{c}} c$, it may raise or lower the income tax $\tau_{\mathrm{f}} y$. This ambiguity can be seen directly from Eq. (15), or

$$
\bar{E}=\tau_{\mathrm{f}} y\left(\bar{k}_{\mathrm{p}}, \bar{k}_{\mathrm{s}}\right)+\tau_{\mathrm{s}} y\left(\bar{k}_{\mathrm{p}}, \bar{k}_{\mathrm{s}}\right)+\tau_{\mathrm{c}} \bar{c}
$$

On the right-hand side of Eq. (17), the second and the third terms are reduced as a result of a higher federal income tax, but the first term may be higher or lower (the familiar property of the Laffer curve for income tax or inflation tax).

Second, a rise in the federal matching grant for local public investment leads to more local public capital stock, more private capital stock, and more private and public consumption in the long run. The reason for these results is simple. The federal matching grant for local public investment creates more incentive for the local government to undertake more investment and accumulate more public capital stock, which in turn improves the productivity of private investment. Thus, in the long run, both local public capital and private capital are increased as a result of a higher federal matching grant for local public investment. As both private and local public capital stocks increase after the rise in the federal matching grant for local public investment, more output is produced and more private consumption obtained. Local public consumption also increases because more income tax and more consumption tax are collected with the rise in private production and private consumption.

Now I turn to a few results which are not so obvious from the model.

Proposition 3. A rise in the local income tax rate $\tau_{\mathrm{s}}$ has ambiguous effects on private capital stock, local public capital stock, private consumption, and local public consumption in the long run. 
This proposition can be verified by using Cramer's rule in (16),

$$
\begin{aligned}
\frac{d k_{\mathrm{p}}}{d \tau_{\mathrm{s}}} & =\frac{\tau_{\mathrm{s}}(1-\alpha)^{-1} y_{22} y_{1}+\left(1-\tau_{\mathrm{f}}-\tau_{\mathrm{s}}\right) y_{12}}{\left(1-\tau_{\mathrm{f}}-\tau_{\mathrm{s}}\right) \tau_{\mathrm{s}}(1-\alpha)^{-1}\left[y_{11} y_{22}-y_{12}^{2}\right]}, \\
\frac{d k_{\mathrm{s}}}{d \tau_{\mathrm{s}}} & =\frac{-\tau_{\mathrm{s}}(1-\alpha)^{-1} y_{12} y_{1}-\left(1-\tau_{\mathrm{f}}-\tau_{\mathrm{s}}\right) y_{2} y_{11}}{\left(1-\tau_{\mathrm{f}}-\tau_{\mathrm{s}}\right) \tau_{\mathrm{s}}(1-\alpha)^{-1}\left[y_{11} y_{22}-y_{12}^{2}\right]},
\end{aligned}
$$

which do not have definite signs because the numerators can be positive or negative while the common denominator is always positive. As for both private and public consumption, their ambiguities follow the ambiguities of the capital stock and output.

The economic intuition for this result is the following: the direct impact of a rise in the local income tax is a reduction in private investment and an increase in local public investment. But the rising public investment also stimulates private investment due to the fact that these two capital inputs are complementary in production. Thus, the net effect of a rise in the local income tax on output production is not clear. Proposition 3 leads to a similar issue regarding the optimal local income tax for financing local public investment as found in different contexts by Barro [2] and Devarajan et al. [4]. Essentially, due to the externality of local public capital on private production, a small income tax as a way of financing local public investment is always justified. But when the income tax rate is rising above a certain point, the corresponding disincentive for private production will outweigh the benefits of public capital formation. Naturally, the optimal choice of a local income tax schedule can be determined by the cost-benefit analysis in a dynamic growth model similar to that in this paper.

PROPOSITION 4. In the long run, the federal matching grant for local public consumption has no effect on private capital stock, local public capital accumulation, private consumption, and local public consumption.

To show this result, I first point out that both private and public capital stocks are independent of the federal matching grant for local public consumption in the long run as in the steady-state equations (12) and (13). Once the long-run public capital stock is determined, the spending on the long-run local public consumption is decided as a residual.

This result is quite counter-intuitive. In general, we expect that a rise in the federal matching grant for local public consumption would lead to locality to divert more local resources from public investment to consumption. This conclusion is a fact which can be derived from many static 
models on local government spending. But what we usually expect does not hold in the long-run analysis based on a sound dynamic structure. In particular, I want to draw attention to the surprising conclusion that this matching grant does not even change local public consumption in the long run. To put it in a policy context, we may question the effectiveness of many federal incentive programs for local welfare and public consumption. In the long run, a matching grant for investment turns out to be more effective in providing more local public consumption than a matching grant for consumption.

Proposition 5. An increase in the local consumption tax has no effect on the long-run capital stocks, but it reduces private consumption and raises local public consumption.

That local consumption tax has no effect on the long-run accumulation of both private and local public capital can be seen directly from the steady-state equations (12) and (13), because the local consumption tax does not appear in these two equations, which determine the long-run capital stocks. Then, from Eq. (14), as the after-tax income, $\left(1-\tau_{f}-\right.$ $\left.\tau_{\mathrm{s}}\right) y\left(\bar{k}_{\mathrm{p}}, \bar{k}_{\mathrm{s}}\right)$, is fixed, consumption has to be reduced corresponding to a rise in the consumption tax. With a higher consumption tax, local public consumption will increase and its magnitude can be derived from Eq. (15): $d E / d \tau_{\mathrm{c}}=\bar{c}>0$. Therefore, a local consumption tax only reallocates a given amount of resources between the private sector and public sector and cannot stimulate either private or public capital accumulation in the long run.

\section{THE MODIFIED ARROW-KURZ UTILITY FUNCTION}

It should be emphasized that many results derived in Sections II and III above depend on the commonly accepted utility function defined in (1). But if the utility function is defined on both local public consumption and local public capital in addition to private consumption (a suggestion from A rrow and Kurz [1]),I then, in the long run, the federal matching grant for local public consumption and a local consumption tax do affect the long-run accumulation of both private and public capital. To make this point clear, let me first extend the model setup to include the A rrow-Kurz utility function

$$
\int_{0}^{\infty}\left[u(c)+v(E)+w\left(k_{\mathrm{s}}\right)\right] e^{-\rho t} d t, \quad 0<\rho<1,
$$

where $w\left(k_{s}\right)$ represents the utility from the services of local public capital stock. The dynamic budget constraints for the representative agent, the local government, and the federal government remain the same as E qs. (6), 
(5), and (3), respectively. The necessary conditions for optimization are modified to be Eqs. (8), (6), (11), and

$$
\begin{gathered}
\dot{E}=\frac{v^{\prime}(E)}{-v^{\prime \prime}(E)}\left[\tau_{\mathrm{s}}(1-\alpha)^{-1} y_{2}\left(k_{\mathrm{p}}, k_{\mathrm{s}}\right)-\rho\right] \\
+\frac{w^{\prime}\left(k_{\mathrm{s}}\right)}{-v^{\prime \prime}(E)}(1-\beta)(1-\alpha)^{-1} .
\end{gathered}
$$

Now, the dynamic system differs from that previous only in Eq. (21). It can be shown as in A rrow and Kurz [1] that, unlike the model in Sections II and III, there may exist multiple equilibria here, so that the nice properties of the unique equilibrium of the previous model disappear with the introduction of $w\left(k_{\mathrm{s}}\right)$ into the utility function. That is to say, Propositions 1 and 2 do not hold any more in the new model. With multiple equilibria, it is necessary to choose a saddle-point equilibrium to linearize the dynamic system above, which amounts to assuming that, at some equilibrium state, $\left(\bar{c}, \bar{E}, \bar{k}_{\mathrm{p}}, \bar{k}_{\mathrm{s}}\right)$, out of the possible few, the $4 \times 4$ matrix, denoted as $M^{\prime}$, has a positive determinant $\Delta^{\prime}$. This is to guarantee that there exists a unique perfect foresight path in the neighborhood of this equilibrium. W ith this assumption, the comparative equilibrium analysis can proceed as usual.

In this selected saddle-point equilibrium, the equilibrium conditions of the new dynamic system are (12), (14), (15), and

$$
\tau_{\mathrm{s}}(1-\alpha)^{-1} y_{2}\left(\bar{k}_{\mathrm{p}}, \bar{k}_{\mathrm{s}}\right) v^{\prime}(\bar{E})-v^{\prime}(\bar{E}) \rho+w^{\prime}\left(\bar{k}_{\mathrm{s}}\right)(1-\beta)(1-\alpha)^{-1}=0 \text {. }
$$

The difference between these equilibrium conditions and those previous is that Eq. (13) has been changed to Eq. (22) here, which implies that the marginal benefit of local public investment, $\tau_{\mathrm{s}}(1-\alpha)^{-1} y_{2}\left(\bar{k}_{\mathrm{p}}, \bar{k}_{\mathrm{s}}\right) v^{\prime}(\bar{E})+$ $w^{\prime}\left(\bar{k}_{\mathrm{s}}\right)(1-\beta)(1-\alpha)^{-1}$, equals the marginal cost of the foregone local public consumption, $v^{\prime}(\bar{E}) \rho$.

With the new utility function, Propositions 4 and 5 are not true any more. In fact:

Proposition 6. With the Arrow-Kurz utility function, an increase in the federal matching grant for local public consumption reduces local public capital, private capital, private consumption, and even (surprisingly) local public consumption in the long run. 
Proof. Totally differentiate (12), (22), (14), and (15):

$\left[\begin{array}{cccc}0 & 0 & \left(1-\tau_{\mathrm{f}}-\tau_{\mathrm{s}}\right) y_{11} & \left(1-\tau_{\mathrm{f}}-\tau_{\mathrm{s}}\right) y_{12} \\ 0 & {\left[\tau_{\mathrm{s}}(1-\alpha)^{-1} y_{2}-\rho\right] v^{\prime \prime}} & \tau_{\mathrm{s}}(1-\alpha)^{-1} y_{21} v^{\prime} & \tau_{\mathrm{s}}(1-\alpha)^{-1} y_{22} v^{\prime}+\frac{1-\beta}{1-\alpha} w^{\prime \prime} \\ -\left(1+\tau_{\mathrm{c}}\right) & 0 & \left(1-\tau_{\mathrm{f}}-\tau_{\mathrm{s}}\right) y_{1} & \left(1-\tau_{\mathrm{f}}-\tau_{\mathrm{s}}\right) y_{2} \\ \tau_{\mathrm{c}} & -1 & \left(\tau_{\mathrm{f}}+\tau_{\mathrm{s}}\right) y_{1} & \left(\tau_{\mathrm{f}}+\tau_{\mathrm{s}}\right) y_{2}\end{array}\right]$

$\times\left[\begin{array}{c}d c \\ d E \\ d k_{\mathrm{p}} \\ d k_{\mathrm{s}}\end{array}\right]$

$=\left[\begin{array}{c}y_{1} d \tau_{f}+y_{1} d \tau_{\mathrm{s}} \\ -y_{2}(1-\alpha)^{-1} v^{\prime} d \tau_{\mathrm{s}}-\left[\tau_{\mathrm{s}}(1-\alpha)^{-2} y_{2} v^{\prime}+(1-\beta) w^{\prime}(1-\alpha)^{-2}\right] d \alpha+(1-\alpha)^{-1} w^{\prime} d \beta \\ y d \tau_{f}+y d \tau_{\mathrm{s}}+\bar{c} d \tau_{\mathrm{c}} \\ -y d \tau_{f}-y d \tau_{\mathrm{s}}-\bar{c} d \tau_{\mathrm{c}}\end{array}\right]$

U sing Cramer's rule in (23) yields

$$
\begin{aligned}
& \frac{d k_{\mathrm{p}}}{d \beta}=-w^{\prime}\left(\bar{k}_{\mathrm{s}}\right)(1-\alpha)^{-1}\left(\Delta^{\prime \prime}\right)^{-1}\left(1+\tau_{\mathrm{c}}\right)\left(1-\tau_{\mathrm{f}}-\tau_{\mathrm{s}}\right) y_{12}\left(\bar{k}_{\mathrm{p}}, \bar{k}_{\mathrm{s}}\right)<0, \\
& \frac{d k_{\mathrm{s}}}{d \beta}=w^{\prime}\left(\bar{k}_{\mathrm{s}}\right)(1-\alpha)^{-1}\left(\Delta^{\prime \prime}\right)^{-1}\left(1+\tau_{\mathrm{c}}\right)\left(1-\tau_{\mathrm{f}}-\tau_{\mathrm{s}}\right) y_{11}\left(\bar{k}_{\mathrm{p}}, \bar{k}_{\mathrm{s}}\right)<0,
\end{aligned}
$$

where $\Delta^{\prime \prime}$ is positive by the assumption of a perfect-foresight equilibrium at $\left(\bar{c}, \bar{E}, \bar{k}_{\mathrm{p}}, \bar{k}_{\mathrm{s}}\right)$, because $\Delta^{\prime \prime}$ is just the product of the four eigenvalues (two positive and two negative for perfect-foresight equilibrium) multiplied by a positive number.

Then, private consumption will be reduced as a result of lower capital stocks and a lower output from Eq. (14). Similarly, the long-run local public consumption is reduced because of a smaller output tax and a smaller consumption tax as in E q. (15).

Q.E.D.

Proposition 6 combined with Proposition 4 provides some strong indication about the effects of a matching grant for local public consumption. In the short run, a matching grant for local public consumption always stimulates public consumption and reduces public investment. In the long run, it either has no effect on the accumulation of private and public capital (when the utility function is independent of local public capital) or 
reduces both private and public capital stocks with the A rrow-Kurz utility function. Furthermore, in the long run, a federal matching grant for local public consumption has either no effect or negative effect on the equilibrium level of local public consumption.

PROPOSITION 7. With the modified Arrow-Kurz utility function, a rise in the consumption tax leads to more private capital and more local public capital.

$$
\begin{aligned}
& \text { Proof. In (23), } \\
& \frac{d k_{\mathrm{s}}}{d \tau_{\mathrm{c}}}=-\left(\Delta^{\prime \prime}\right)^{-1}\left(1-\tau_{\mathrm{f}}-\tau_{\mathrm{s}}\right) y_{11}\left(\bar{k}_{\mathrm{p}}, \bar{k}_{\mathrm{s}}\right)\left[\tau_{\mathrm{s}}(1-\alpha)^{-1} y_{2}-\rho\right] v^{\prime \prime}(E)>0,
\end{aligned}
$$

which is positive because the term $\left[\tau_{s}(1-\alpha)^{-1} y_{2}-\rho\right]$ has to be negative for the equilibrium condition in (22) to be maintained. The rise in private capital stock follows:

$$
d k_{\mathrm{p}} / d \tau_{\mathrm{c}}=-y_{11} y_{11}\left(d k_{\mathrm{s}} / d \tau_{\mathrm{c}}\right)>0
$$

Proposition 6 stands in sharp contrast to Proposition 5 in the previous section. Without the A rrow-K urz utility function, Proposition 5 has shown that long-run capital stocks are independent of consumption tax. With the A rrow-Kurz utility function, the rising local government's revenue as a result of a higher consumption tax will be allocated to both local public consumption and local investment in both the short run and the long run. Unlike equilibrium condition (13) where long-run local public capital does not depend on the utility from local public consumption, the new equilibrium condition of (22) underlies the balance between local public investment and local public consumption. In particular, if a higher consumption tax only gives rise to a rise in local public consumption, the marginal utility from the unchanged local public capital stock will be higher as seen clearly from Eq. (22). To maintain this equilibrium condition, more local revenue will be invested in local public capital accumulation. A s local public capital stock increases, the marginal productivity of private investment also rises. Therefore, all capital stocks and output in the long run will be higher as a result of a higher consumption tax.

\section{SUMMARY}

In a modified optimal growth model with both private and local public capital accumulation, this paper has made a preliminary attempt to examine how federal and local income taxes, local consumption tax, and federal matching grants for local public consumption and local public investment affect the long-run equilibrium (equilibria) of private consumption, private capital accumulation, local public consumption, and local public capital stock. The main findings are summarized in Table 1 according to the two 
TABLE 1

L ong-R un $E$ ffect of Taxes and $G$ rants

Exogenous variables

\begin{tabular}{|c|c|c|c|c|c|c|c|c|c|c|}
\hline \multirow{2}{*}{$\begin{array}{c}\text { Endogenous } \\
\text { variables }\end{array}$} & \multicolumn{2}{|c|}{$\tau_{f}$} & \multicolumn{2}{|c|}{$\tau_{\mathrm{s}}$} & \multicolumn{2}{|c|}{$\tau_{\mathrm{c}}$} & \multicolumn{2}{|c|}{$\alpha$} & \multicolumn{2}{|c|}{$\beta$} \\
\hline & (i) & (ii) & (i) & (ii) & (i) & (ii) & (i) & (ii) & (i) & (ii) \\
\hline $\bar{k}_{\mathrm{p}}$ & - & - & $?$ & $?$ & 0 & + & + & + & 0 & - \\
\hline $\bar{k}_{\mathrm{s}}$ & - & - & $?$ & $?$ & 0 & + & + & + & 0 & - \\
\hline $\bar{c}$ & - & - & $?$ & $?$ & - & $?$ & + & + & 0 & - \\
\hline $\bar{E}$ & $?$ & $?$ & $?$ & $?$ & + & + & + & + & 0 & - \\
\hline
\end{tabular}

definitions of the utility function, where columns (i) and (ii) report the results corresponding to the usual utility function and the A rrow-Kurz utility function, respectively.

Theoretically, both types of preferences are reasonable even though it is more often the case that the utility function is defined in private and public consumption. Since the implications of various policies are so different as a result of these two specifications of preferences, the issues can only be settled empirically in future studies.

\section{APPENDIX: PROOF OF PROPOSITION 2}

I need to show that there are two positive eigenvalues and two negative eignevalues corresponding to the two jumping variables, $c$ and $E$, and the two state variables, $k_{\mathrm{p}}$ and $k_{\mathrm{s}}$; see Buiter [3]. Linearizing the four differential equations of the dynamic system around the steady-state values,

$$
\begin{aligned}
& {\left[\begin{array}{c}
\dot{c} \\
\dot{E} \\
\dot{k}_{\mathrm{p}} \\
\dot{k}_{\mathrm{s}}
\end{array}\right]=\left[\begin{array}{cccc}
0 & 0 & \frac{u^{\prime}()}{-u^{\prime \prime}()}\left(1-\tau_{\mathrm{f}}-\tau_{\mathrm{s}}\right) y_{11} & \frac{u^{\prime}()}{-u^{\prime \prime}()}\left(1-\tau_{\mathrm{f}}-\tau_{\mathrm{s}}\right) y_{12} \\
0 & 0 & \frac{v^{\prime}()}{-v^{\prime \prime}()} \tau_{\mathrm{s}}(1-\alpha)^{-1} y_{21} & \frac{v^{\prime}()}{-v^{\prime \prime}()} \tau_{\mathrm{s}}(1-\alpha)^{-1} y_{22} \\
-\left(1+\tau_{\mathrm{c}}\right) & 0 & \left(1-\tau_{\mathrm{f}}-\tau_{\mathrm{s}}\right) y_{1} & \left(1-\tau_{\mathrm{f}}-\tau_{\mathrm{s}}\right) y_{2} \\
\tau_{\mathrm{c}} & -1 & \left(\tau_{\mathrm{f}}+\tau_{\mathrm{s}}\right) y_{1} & \left(\tau_{\mathrm{f}}+\tau_{\mathrm{s}}\right) y_{2}
\end{array}\right] } \\
& \times\left[\begin{array}{c}
c-\bar{c} \\
E-\bar{E} \\
k_{\mathrm{p}}-\bar{k}_{\mathrm{p}} \\
k_{\mathrm{s}}-\bar{k}_{\mathrm{s}}
\end{array}\right] .
\end{aligned}
$$

Let $M$ denote the $4 \times 4$ matrix in (A 1) and let $\lambda_{1}, \lambda_{2}, \lambda_{3}$, and $\lambda_{4}$ denote the four eigenvalues of this dynamic system. It is well known that the 
product of these four eigenvalues equals the determinant of matrix $M$ (denoted as $\Delta$ )

$$
\begin{aligned}
\lambda_{1} \lambda_{2} \lambda_{3} \lambda_{4} & =\Delta=\frac{u^{\prime}(\bar{c})}{u^{\prime \prime}(c)} \frac{v^{\prime}(\bar{E})}{v^{\prime \prime}(\bar{E})} \tau_{\mathrm{s}}\left(1+\tau_{\mathrm{c}}\right)(1-\alpha)^{-1}\left(1-\tau_{\mathrm{f}}-\tau_{\mathrm{s}}\right) \\
{\left[y_{11} y_{22}-y_{12}^{2}\right] } & >0
\end{aligned}
$$

which is to say, there are three possibilities: no negative eigenvalue, two negative eigenvalues, or four negative eigenvalues. But, the sum of the four eigenvalues is equal to the trace of matrix $M$, which turns out to be positive:

$$
\lambda_{1}+\lambda_{2}+\lambda_{3}+\lambda_{4}=\left(1-\tau_{\mathrm{f}}-\tau_{\mathrm{s}}\right) y_{1}\left(\bar{k}_{\mathrm{p}}, \bar{k}_{\mathrm{s}}\right)+\left(\tau_{\mathrm{f}}+\tau_{\mathrm{s}}\right) y_{2}\left(\bar{k}_{\mathrm{p}}, \bar{k}_{\mathrm{s}}\right)>0
$$

Therefore, at least one eigenvalue is positive. Combining (A 2) with (A 3) narrows down the possibilities to two: either no negative eigenvalue (all four eigenvalues are positive) or two negative eigenvalues. To show that the latter is true, I need the condition that the product, $\lambda_{1} \lambda_{2} \lambda_{3}+\lambda_{1} \lambda_{2} \lambda_{4}$ $+\lambda_{1} \lambda_{3} \lambda_{4}+\lambda_{2} \lambda_{3} \lambda_{4}$, equals the sum of all principal minors of order three in matrix $M$. Some tedious calculation yields

$$
\begin{aligned}
\lambda_{1} \lambda_{2} \lambda_{3}+ & \lambda_{1} \lambda_{2} \lambda_{4}+\lambda_{1} \lambda_{3} \lambda_{4}+\lambda_{2} \lambda_{3} \lambda_{4} \\
= & \frac{v^{\prime}(\bar{E})}{v^{\prime \prime}(\bar{E})} \tau_{\mathrm{s}}(1-\alpha)^{-1}\left(1-\tau_{\mathrm{f}}-\tau_{\mathrm{s}}\right)\left[y_{12} y_{2}-y_{22} y_{1}\right] \\
& +\frac{u^{\prime}(\bar{c})}{u^{\prime \prime}(\bar{c})}\left(1-\tau_{\mathrm{f}}-\tau_{\mathrm{s}}\right)\left[\left(1+\tau_{\mathrm{c}}\right)\left(\tau_{\mathrm{f}}+\tau_{\mathrm{s}}\right) y_{1} y_{12}\right. \\
& \left.\quad-\tau_{\mathrm{c}}\left(1-\tau_{\mathrm{f}}-\tau_{\mathrm{s}}\right)\left(y_{2} y_{11}-y_{1} y_{12}\right)-\left(\tau_{\mathrm{f}}+\tau_{\mathrm{s}}\right) y_{2} y_{11}\right],
\end{aligned}
$$

which is negative. Thus, at least one eigenvalue is negative. $W$ ith the results regarding the determinant and the trace of matrix $M$, the only possibility is that there are two negative eigenvalues and two positive eigenvalues, or stated differently, there exists a unique perfect foresight equilibrium in this dynamic system.

Q.E.D.

\section{REFERENCES}

1. K. A rrow and M. Kurz, "Public Investment, the R ate of Return, and Optimal Fiscal Policy," J ohns H opkins U niv. Press (for R esources for the Future), Baltimore (1970).

2. R. Barro, Government spending in a simple model of endogenous growth, Journal of Political Economy, 98, S103-S125 (1990). 
3. W. Buiter, Saddlepoint problems in continuous time rational expectation models: A general method and some macroeconomic examples, Econometrica, 52, 665-680 (1984).

4. S. D evarajan, V. Swaroop, and H. Z ou, The composition of public spending and economic growth, Journal of Monetary Economics, 37, (1996).

5. E. Gramlich, State and local governments and their budget constraint, International Economic Review, 10, 163-182 (1968).

6. E. Gramlich, and H. Galper, State and local fiscal behavior and federal grant policy, Brookings Papers on Economic Activity, 1, 15-65 (1973).

7. R. Inman, Toward an econometric model of local budgeting, in "National Tax A ssociation: Proceedings of the Sixty-Second Conference on Taxation" (1971).

8. P. M ieszkowski, and W. Oakland, (E ds.), "Fiscal Federalism and Grants-in-A id," U rban Institute, Washington, DC (1979).

9. P. Romer, Increasing returns and long-run growth, Journal of Political Economy, 94, 1002-1037 (1986).

10. H. R osen, (E d.), "Fiscal Federalism: Q uantitative Studies," U niversity of Chicago Press, Chicago (1988).

11. J. Wilde, The expenditure effects of grant-in-aid programs, National Tax Journal, 21, 340-348 (1968).

12. J. Wilde, Grants-in-aid: The analytics of design and response, National Tax Journal, 24, 143-155 (1971).

13. H. Z ou, D ynamic effects of federal grants on local spending. Journal of Urban Economics, 36, 98-115 (1994).

14. H. Zou, O ptimal design of federal grants to localities, mimeo, Policy Research Department, World Bank (1993). 